\title{
Towards Progressive and Dynamic Multicultural Education: Teachers’ Awareness of Multicultural Education in South Korean Schools
}

\author{
Sunnie Lee Watson ${ }^{1, *} \&$ Gilbert C. Park ${ }^{2}$ \\ ${ }^{1}$ Curriculum and Instruction, College of Education, Purdue University, USA \\ ${ }^{2}$ Department of Educational Studies, Teachers College (TC), Ball State University, Muncie, \\ Indiana, USA \\ *Corresponding author: Curriculum and Instruction, College of Education, Purdue University, \\ USA. E-mail: sunnieleewatson@purdue.edu
}

Received: October 8, 2014 Accepted: November 16, 2014 Published: January 22, 2015

doi:10.5296/ije.v7i1.6430ＵRL: http://dx.doi.org/10.5296/ije.v7i1.6430

\begin{abstract}
While multicultural education was first started in the United States by concerned activists and educators to secure social justice for both presently and historically marginalized groups, educators in other parts of the world are seeing it as a tool to better meet the needs of their own marginalized students. Such is the case in South Korea, which has experienced rapid demographic changes in recent decades. This article explores how South Korean teachers understand the increasing diversity in South Korean society and examines their perspectives on multicultural approaches in schools using a survey of 86 schoolteachers in three different cities. The findings suggest a need for politicalization of multicultural education beyond mere tools to address immediate problems facing the cultural others in Korea.
\end{abstract}

Keywords: Diversity, Multicultural education, Teacher Professional Development, South Korean education 


\section{Introduction}

South Korea has boasted relative ethnic and racial homogeneity for some time, and its schools long celebrated the concept of Danil Minjok (Ethnic Uniformity or One-Blood Ethnicity) as the basis for national pride and identity (Watson, Park \& Lee, 2011; Moon, 2010). This pride was challenged as the nation experienced an explosion of cultural diversity in recent years. For instance, South Korea's Ministry of Education and Human Resources Development (MEHRD) reported in 2006 that the number of multicultural students (Damunhwa Haksang or those from families where at least one of the parents are not Korean born) increased by 30\% or more in the early 2000s and 68\% in 2005 alone. In 2008, MEHRD reported 300\% growth of such students in Korean schools from 2005 to 2008. Many of these multicultural students come from families where one or both of the parents emigrated from different parts of Asia. Some of the parents settled in Korea after marrying a Korean citizen while others sought to improve their economic circumstances by seeking employment and over-staying their working visa to become undocumented or illegal immigrants (Moon, 2010; Tschong, 2009; Won, 2008). Still others came to Korea as refugees from North Korea to escape both economic and political hardships. In response to the rapid demographic changes, South Korean schools are seeking to help these multicultural students become incorporated into the South Korean mainstream using multicultural education (Damunhwa Kyoyook). Using a survey of eighty-six teachers, this study looks at how South Korean schoolteachers view the increasing diversity in South Korea and the multicultural approaches utilized in their schools. The goal is to suggest some ways to better prepare these teachers who are working with multicultural students by drawing from American immigrant experiences in school.

\subsection{Literature Review: Schooling of Immigrants in Two Countries}

Drawing from American immigrant schooling where schools played an important role in Americanizing immigrant students may be useful in discussing the South Korean approach to their immigrants in schools. In the early twentieth century, when a large influx of immigrants from eastern and southern European countries came to the United States, for example, American schools responded by seeking to transform these "aliens into Americans" (Fass, 1989). Such transformation required specific instructions on acquiring characteristics of what the society imagined Americans to be, including how to clean, pray, and talk like Americans (Olneck, 2004). Driving the transformation is the underlying perception that the foreign culture is a threat to national identity, and this threat must be address through assimilation into American society by eradicating the foreignness. Partly because of such efforts, these "aliens" became white Americans over time as their ethnic ties weakened, and the need for society to incorporate them into the American racial hierarchy as whites heightened (Lew, 2006; Lee, 2005; Reodiger, 2005; Portes \& Rumbaut, 2001). Similarly, the very centralized South Korean educational system sought to transform multicultural aliens into Koreans.

The goals of South Korean multicultural education are clearly defined in the 2008 report by the Ministry of Education, Science, and Technology (MEST). Much like the American counterpart, the first and foremost goal aims to reduce the educational disadvantages facing multicultural students and to help them adapt to Korean society. The other notable goals are 
to promote cultural sensitivity and understanding among general students and to assist multicultural students in becoming globally competent and bilingual. To meet these goals, roughly three million American dollars were allocated to support multicultural education related research, produce Korean language textbooks for multicultural students, and incorporate cultural sensitivity programs in the nation's pre-service teacher training and in-service professional development program. Outside of schools, a network of local multicultural education and support centers were created to facilitate the transition of multicultural family members into the Korean mainstream, including after school and counseling programs. Also, like American efforts, South Korean efforts seem to view the presence of multicultural students as a threat to national identity and transforming them into the Koreans is their response. Unlike white immigrants who became Americans in the past, however, it is not clear if multicultural students will be fully transformed as Koreans as in the Danil Minjok. A close examination of non-white immigrants since 1965 suggests otherwise. White immigrants' straight-line assimilation path where immigrants become fully incorporated into American mainstream is only one of many options for today's immigrants of color. Instead, other scholars (Park, 2011; Tuan, 1998; Olsen, 1997) point to race as a factor in the Americanization process where schools actively construct white Americans to mean "real" Americans thereby leaving hyphenated American identities for many immigrants of color as less than authentic Americans.

Due to the recency of the current influx of immigrants in South Korea, the outcome of the transformation remains to be to seen; nevertheless, the insistency on Danil Minjok in South Korean society and schools may situate multicultural students as less than authentic Koreans as was the case for immigrants of color as less than authentic Americans. With this in mind, a growing number of activists, educators, and scholars voice concerns about South Korean multicultural education. Some of them (Lee \& Shon, 2011; Lim, 2010; Kang 2008) charge that the approach solely places blame on the multicultural students' cultural differences and their inability to acculturate quickly enough. Others (Watson et al., 2011; Choi, 2010) argue that the current approach falls short in addressing Danil Minjok ideology that demarcates multicultural students as cultural others who can not be authentic Korean. Specifically, this article builds upon the authors' (2011) previous research on South Korean pre-service teachers' attitudes toward increasing diversity where we called for critical examination of the meaning of Koreaness by focusing on the in-service teachers who are already in the field. This article seeks to add to this body of literature and aims to suggest concrete ways to better prepare in-service teachers. To do so, we looked at how a group of eighty-six in-service teachers understand the challenges and issues in working with multicultural students.

\subsection{Theoretical Framework: Critical Multiculturalism}

While multicultural education was first started by concerned activists and educators to secure social justice through education, the term began to represent different goals and means in the U.S over time. There is an approach that aims to reduce intergroup conflicts and promote social harmony by teaching about the differences and similarities. Others look to foster academic success by using non-mainstream students' cultures and to instill a sense of cultural pride. Still others purport to give access to the mainstream by teaching the culture of the 
dominant group. While these approaches have their own merits, we agree with the multiculturalists' (Grant \& Sleeter, 2010; Ahn, 2009; Banks, 2002, Davidman \& Davidman, 1997; Grant, 1994) aim for concepts like equity and social justice beyond incorporating cultural others and validating cultural diversity. Among them is Grant (1994) who argues that multicultural education is a "philosophical concept and an educational process" that promotes equal educational opportunity for all students including those who are both historically and presently underserved in our schools (p. 4).

Other leading scholars like Sleeter (1995), Neito (1996), and Ladson-Billings (1995) agree with Grant as they seek to break down individual, curricular, and institutional barriers facing students of marginalized groups beyond the confines of schools. For instance, Neito (1996) states that there are "practices and policies that advantage some students at the expense of others” (p. 315). Similarly, Sleeter (1995) calls for understanding the power relationships both in schools and larger society to highlight the unequal distribution of power and privilege. In her argument for culturally relevant pedagogy, Ladson-Billings (1995) echoes the concerns by suggesting that multicultural education should produce academic excellence while preparing students for social actions beyond incorporating their cultures. With these in mind, Gorski (2006) posits that multicultural education is a "political movement that attempts to secure social justice" for all students that recognizes that both individual and institutional biases against non-mainstream students exist and that these must be overcome to eliminate educational inequalities through a comprehensive school reform (p.165).

Regarding the multicultural students in South Korea, these multiculturalists are not satisfied with promoting ethnic pride and co-ethnic cohesion but seek to empower the multicultural students to critique and challenge the forces that lead them away from the Korean mainstream. In order for such empowerment to take place, we argue that the in-service teachers who work with them directly must also experience their own empowerment through multicultural education. This empowerment is where teachers begin to see themselves as active participants of change for social justice. It requires what Freire (1999) calls, "critical consciousness" where teaching is viewed as a political act, which can be a tool of the oppressors to facilitate their dominance as well as of the oppressed to resist domination. This view on teaching resists treating students as "receiving objects" of learning but instead promotes active learning where teachers and students teach and learn together within democratic social relations (Kinchloe, 2008). This requires the South Korean educators to position themselves along with the multicultural students (who are demarcated as illegitimate Koreans) and critically examine their own worldviews whether or not it helps or resists the oppression they and their students face (Watson et al., 2011).

Informed by this view on multicultural education, we looked for what Rodriguez (1998) calls, "resistance to ideological and pedagogical changes" in collecting and analyzing the data. The "resistance to ideological change" is where the in-service teachers would not want, or do not see the need, to change their own worldviews regarding diversity in Korea. Similarly the "resistance to pedagogical change" refers to the times when the educators narrowly define good teaching to only mean effective delivery of content. Occurrences of these resistances would indicate the need for critical engagement and empowerment as discussed above. It also 
calls for what Gorski (2006) calls "politicalization” of multicultural education where educators become activists for themselves and their students to "fill the gap in perception and experience that exists between the well-intentioned educators and policy-makers and the despite-the-good-intentions-disenfranchised students (p. 175).”

\section{Methodology}

The goal of this study was to understand South Korean in-service teachers' awareness of the newly emerging multicultural society in South Korea and their perspectives toward multicultural education in South Korean K-12 schools. With this goal, the research questions of this study were:

1. How aware are Korean teachers of the multicultural issues in Korean society and education?

2. How comfortable do Korean teachers feel about the multiculturalization of Korean society? Do teachers have certain attitudes or perceptions of Korean society that may challenge them from successfully using multicultural approaches in education?

3. What perspectives do Korean teachers have about multicultural education?

4. How prepared and ready do Korean teachers feel about teaching in classrooms with diversity and addressing multicultural issues when they arise? What kinds of preparation, training or support do teachers want for implanting multicultural approaches in their classrooms?

\subsection{Instrument}

A survey instrument for exploring these research questions was developed based on a review of literature. Through the process of member checking and peer debriefing with in-service teachers, school administrators and teacher educators in South Korea, a set of survey questions for exploring South Korean in-service teachers' perspectives on diversity and multicultural education were identified.

Overall, twenty questions were selected for the final survey questionnaire that we used for the study, which included a combination of closed and open-ended questions. Six out of twenty questions were open-ended questions about teachers' perspectives on multiculturalism in South Korean and multicultural education in South Korean K-12 schools.

\subsection{Participants}

In total, 86 in-service teachers volunteered to participate in the study. The study participants were in-service teachers that were working towards a master's degree at teacher training universities in South Korea during the academic year of 2011-2012. The researchers visited three different universities in three different cities (Seoul, Bundang and Chungju) for the data collection. All three universities are considered leading teacher education institutions in South Korea and teachers trained at these schools are considered strong members of the K-12 
educational community.

Among the 86 participants, 76 participants were female and 10 were male participants, which is an accurate representation of how female focused the teaching profession is in South Korea. The age range of the participants varied from age 25 to 52 . 33 teachers were elementary school teachers, 16 were middle school teachers and 37 taught at the high school level. 29 English teachers, 17 homeroom teachers (teaches all elementary subjects), 13 music teachers, 7 science teachers, 3 art teachers, 2 Korean literature, 2 Chinese as a foreign language, 1 computer education, 1 geology, and 1 social studies teacher completed the survey.

\subsection{Data Collection}

In-service teachers in teacher education graduate degree programs at three teacher-training universities in South Korea participated in the survey questionnaire about their perspectives on the newly emerging multicultural society in South Korea and their thoughts on multicultural education in Korean schools.

The questionnaires were distributed to those in-service teachers that showed interest during class breaks and were collected after class. Voluntary informed consent was acquired from all participants, informing that they had the right to withdraw from the study at any time during the study, and the teachers' anonymity was protected with the confidentiality of the data as well. The data was collected throughout the fall and spring semesters of 2011-2012.

The survey instrument consisted of both closed and open-ended survey questions. Closed question responses of the questionnaire were analyzed as nominal and ordinal data (Fink, 2002; Fowler, 2014), by placing participants into ordered or unordered categories, and the questions that were numerically calculated were charted for ease of representation.

\subsection{Data Analysis}

Grounded theory method of inquiry (Glaser, 2008; Glaser \& Strauss, 2009) was used in analyzing the responses of the open-ended questions of the survey questionnaire, which guided the researchers to synthesize and interpret the written survey responses and accurately portray our understanding of the in-service teachers' perspectives on diversity and multicultural education.

In order to achieve saturation with the categories of themes that emerged in the survey responses, researchers reevaluated these categories and themes at multiple points of data analysis. In this way, the use of grounded theory allowed the establishment of themes across the participants' data and therefore understanding of the critical underlying issues was reached.

Overall, the grounded theory method helped researchers see the relationships that were revealed through the data, generate statements about the suggestions and implications of our data analyses, and also guided us to obtain a better understanding of the Korean in-service teachers dispositions and thoughts about the newly emerging multicultural society and South Korean education (Charmaz, 2005; Denzin \& Lincoln, 2005). 


\section{Results}

The survey responses show that participants are aware of the increasing diversity in Korean society and the challenges associated with this new development but are not very sure about how they feel about this change in South Korean society. The results also show that teachers think that multicultural education is an important aspect of Korean society and schools. The teachers did not feel that they were currently prepared to teach with multicultural approaches; however, they showed strong interest in professional development for learning specific multicultural approaches and obtaining multimedia resources to successfully implement multicultural education in their classrooms.

3.1 Research Question 1. How aware are South Korean teachers of the multicultural issues in Korean society and education?

Regarding the first research question, the participants were asked how they felt immigrant workers, illegal immigrants, or internationally married people were perceived or treated in South Korean society. Over $90 \%$ of the teachers responded that they felt that these people often faced unjust situations.

Table 1. Responses for questionnaire item: How are immigrant workers, illegal immigrants or internationally married people or multicultural families treated in Korean society?

\begin{tabular}{lcc}
\hline & Percentage & Count \\
\hline Do not face unjust treatment at all & $0.0 \%$ & 0 \\
Do not face unjust treatment much & $8.0 \%$ & 7 \\
Face unjust treatment often & $73.6 \%$ & 64 \\
Face unjust treatment very often & $18.4 \%$ & 16 \\
\hline
\end{tabular}

The teachers were also asked if they had any kind of experience with children or students from multicultural families in their teaching or personal lives, and what were their experiences with those children's school life and academic achievement. Almost $60 \%$ of the participants indicated that they had no experience of any kind. However, those who said they had experience shared that they felt that these students did average in their school lives overall (적응도), but very much struggled with academic achievement.

Table 2. Responses for questionnaire item: Do you have any experience in working with students or children from multicultural families? How were their academic achievement and school life?

\begin{tabular}{ccccccc}
\hline & $\begin{array}{c}\text { Very } \\
\text { high }\end{array}$ & High & Average & Low & Very low & $\begin{array}{c}\text { No } \\
\text { experience }\end{array}$ \\
\hline $\begin{array}{c}\text { Academic } \\
\text { Achievement } \\
\text { Ability to } \\
\begin{array}{c}\text { Function in } \\
\text { School }\end{array}\end{array}$ & $3.5 \%(3)$ & $3.5 \%(3)$ & $11.6 \%(10)$ & $20.9 \%(18)$ & $1.2 \%(1)$ & $59.3 \%(51)$ \\
\hline
\end{tabular}


Teachers shared various responses to questions about experience with multicultural students, focusing mostly on their experiences with using multicultural approaches in their classrooms. Many responses talked about tolerance, respect, and embracement of other cultures and ethnicities. The discussion on how in modern society, families look different from traditional families was a very popular response as well. Various subject teachers, such as music, art, literature and social studies, talked about discussing the various cultures, folk music, art and clothes and food. One teacher specifically talked about using Anne Frank's diary and the chapter on the holocaust to talk about tolerance and diversity. Some teachers had experience with helping North Korean refugee students to learn language and culture. There were several comments about the occasional use of media or videos in the classrooms. Two teachers talked specifically about having Chinese or Thai teachers come in to talk about Chinese or Thai culture and food. The classes were only three hours a semester. Many responses also showed that teachers did not have much experience in multicultural education, and that it was hard to find time to implement it due to academic achievement being heavily based on standardized testing.

\subsection{Research Question 2. How comfortable do Korean teachers feel about the increasing} diversity and multiculturalization of Korean society?

To further understand teachers' attitudes and perceptions on diversity in Korean society and multicultural approaches in education, the survey asked questions about teachers' perspectives on the nation's traditional identity of Danil Minjok (one blood ethnicity) and how comfortable they felt about the multiculturalization of Korean society.

When asked, 'Regarding the members of Korean society, do you agree with the perception of Korea's national identity as Danil Minjok regarding the members?', many teachers opposed this identity and indicated disagreement. $71.3 \%$ of the respondents disagreed with the Danil Minkok identity, including $5.7 \%$ of respondents that indicated strong disagreement. Only $27.6 \%$ agreed to this identity. Given the long history of the Korean society being very proud of the one blood ethnicity tradition and the emphasis of this identity in the Korean educational system, this is a very interesting result.

While the identity of Danil Minjok was not something that teachers agreed with, teachers were not so sure if they felt very comfortable with the increasing diversity and multiculturalization of South Korean society. The majority of the teachers (54.7\%) indicated that they felt undecided about multiculturalization. The results from Research Question 1 along with the additional written responses from the survey indicated that teachers have had very limited life and professional experience with diversity and multicultural education and therefore have not had many opportunities to reflect on how they felt about diversity.

Around $20 \%$ of the teachers expressed that they felt comfortable or very comfortable with the multiculturalization of Korean society, while more than $25 \%$ of the teachers responded that they felt uncomfortable or very uncomfortable with the increasing diversity. Overall, the results showed that teachers were aware of the changing demographics of Korean society and societal issues that came along with this change but were having difficulty fully embracing it at a more personal level. 
Table 3. Responses for questionnaire item: How comfortable do you feel about the multiculturalization of Korean society?

\begin{tabular}{lcc}
\hline & Percentage & Count \\
\hline Feels very natural and comfortable & $3.5 \%$ & 3 \\
Feels natural and comfortable & $16.3 \%$ & 14 \\
Undecided & $54.7 \%$ & 47 \\
Feels unnatural and uncomfortable & $25.6 \%$ & 22 \\
Feels very unnatural and uncomfortable & $0 \%$ & 0 \\
\hline
\end{tabular}

3.3 Research Question 3. What attitudes and perspectives do South Korean teachers have about multicultural education in schools?

In regards to our third research question, we surveyed teachers on how important they felt multicultural education was in K-12 schools and for whom multicultural education is for. In addition, they were asked about the purpose of multicultural education and what kinds of instructional approaches should be used for multicultural education.

Table 4. Responses for questionnaire item: How important is multicultural education in Korean K-12 school education?

\begin{tabular}{lcc}
\hline & Percentage & Count \\
\hline Very important & $47.1 \%$ & 41 \\
Important & $51.7 \%$ & 45 \\
Average & $1.1 \%$ & 1 \\
Unimportant & $0 \%$ & 0 \\
Very unimportant & $0 \%$ & 0 \\
\hline
\end{tabular}

Almost all teachers agreed that multicultural education is important or very important in current Korean K-12 education. Only 1.1\% responded that multicultural education was of average importance and no respondent replied that it was not important. These findings were very consistent with the teachers showing strong concern about how inadequately immigrant or minority rights are handled in South Korean society and teachers' shared concern that the children and students from multicultural families have a strong tendency to struggle in schools, particularly in academic achievement.

To the question on for whom multicultural education in Korean schools is for, the majority of the respondents responded that multicultural education was for all members of the world, in a global sense, rather than a specific group of people or nation, to live peacefully. The second most stated response was that it is primarily for the members of Korean society to face the reality of multiculturalization, and therefore become a more harmonious and open society, moving away from the traditionally closed community. Some stated that multicultural education should serve the students from multicultural families so they can overcome challenges in Korean society and therefore should focus on supporting and providing equal opportunities for these students. Others shared that it was more about upholding the belief and notion of tolerance and respect for one another, rather than a specific group of people. 
Several teachers indicated that it should be for the future generation that live in a world where national boundaries are much less important than now.

Related to these responses, teachers' perspectives on the purpose of multicultural education was focused mostly on "creating a harmonious human society" where people of all kinds "coexist in a peaceful manner". It was interesting to see how many teachers viewed the notion of multicultural education as more of a global concept, rather than focusing on the South Korean context. Almost half of the respondents indicated the notion of global, transnational, and worldwide, in their response on the goal for multicultural education. These responses included comments such as "it is about understanding humanity... and overcoming the prejudices we have based on the differences in color and culture”. Another large group of teacher respondents remarked on the need for multicultural education in schools for supporting minority students in particular, saying that "we need to focus on a mindset change in schools that the minority students are just as Korean as anyone else" and "we should help students learn the concept of respect and tolerance, so we can come to embrace one another." Other teachers identified the idea that Korean society is moving forward and becoming more mature in dealing with diversity, writing that "the diversity in our society needs to be viewed as a positive, rather than a negative”, and that multiculturalism was inevitable for Korea to stay competent in the current global society.

As for the question on what kind of pedagogical approaches would be most effective for multicultural education in Korean schools, teachers mostly responded that an authentic, real-life focused curriculum was needed for making meaningful change in students. Teachers indicated that the most impactful way to change student attitudes was to help students to see the unjust situations minorities often face in Korean society first hand, and therefore, something along the lines of fieldwork-based experiences were needed. The teachers also indicated the need for an interdisciplinary approach for multiculturalism, saying that this multicultural approach should be embedded in all subjects, not just in social studies or civic education.

Some responses discussed the limitations schools might have on this issue. "For these types of topics... the parents' attitudes are a much more important influence than the formal education at school", "I know that some teachers feel awkward and uncomfortable discussing these issues, so they just avoid covering it in the classroom.”

3.4 Research Question 4. How prepared do Korean teachers feel about teaching in classrooms with diversity and addressing multicultural issues? What kinds of preparation, training or support are needed for teachers to use multicultural approaches in the classrooms?

In order to understand how well Korean teachers feel prepared about using multicultural approaches in the classroom, open-ended questions were asked on whether teachers had ever used multicultural approaches in their teaching, and how they were used. We also asked how teachers could be better prepared, trained or supported to effectively use multicultural approaches in teaching. 
Only 29 of the participants out of the 86 participants responded that they had been in a context that needed a multicultural education approach. More than 50 teachers indicated that they have not been in a situation where they used or learned to use multicultural teaching approaches. For the teachers who had experience, these experiences were very minimal. The responses were very similar to the responses in Research Question 1, focusing on the introduction to music, art, literature, and history of different countries. Most of these responses showed that many teachers did not have authentic experience with multicultural education.

There were three large categories in the answers to the question on how Korean teachers would like to be trained or supported in the use of multicultural approaches in teaching: the need for developing a strong curriculum and multimedia materials, strong teacher training and human resources support, and a change in social atmosphere and mindset change towards diversity and multiculturalism.

A strong interdisciplinary multicultural education curriculum was strongly desired by teachers. Many respondents reiterated the need for school curriculum revision within social studies in particular, as well as related subjects, so that they would have a multicultural education aspect. The development of multimedia materials for all teachers to use freely in their classes was also a very popular response. Websites, books, videos, interactive presentations discussing diversity and multiculturalism were discussed as highly desirable resources that teachers could use in classrooms.

Teachers also felt that professional development for specific multicultural teaching approaches was critical. They described the need for authentic experiences in more authentic settings, field experiences and volunteering opportunities. There were many requests for mandatory teacher development and training sessions to get specific strategies and techniques to implement multicultural approaches in teaching. Many described their feeling of "just trying to do the right thing [regarding multicultural education], without much support, resources, knowledge or understanding”. Several teachers felt providing human resources in schools devoted to multicultural education might be a good way to help with teacher training.

Finally, many teachers emphasized the importance of a societal mindset change. They felt that unless the society and public as a whole has the desire to change, schools can only do so much, and that the attitude change towards how we view diversity or multiculturalism is critical in teachers' use of multicultural approaches in schools, saying that "Our society needs to understand why multicultural education is so important. Then it'll all come along very easily”.

\section{Discussion}

The results show that most of the participants agreed that the multicultural students in South Korea face unjust treatment, yet there was evidence for resistance to both ideological and pedagogical changes. The resistance to ideological change came in the form of locating the problem facing multicultural students on the cultural differences. Similarly, the resistance to 
pedagogy changes came in the form of the sense of powerlessness as teaching is reduced into delivery of content knowledge instead of a means for growth of individual learners as well as societal change. With these in mind, we argue for politicization of multicultural education that empowers South Korean educators to become agents of change instead of innocent bystanders of the forces that marginalizes their multicultural students.

The first identified trend is the identification of cultural difference as the problem. Almost all of the teachers, 98\%, felt that multicultural education was important to foster a more harmonious society where people of different backgrounds co-exist peacefully while respecting and tolerating differences. This understanding of multicultural education parallels what Grant and Sleeter (2003) call "teaching the exceptional and culturally different" and "human relations" approaches to diversity. The first approach, "teaching the exceptional and culturally different," aims to help students to achieve in school by building bridges between the school and students' backgrounds. The "human relations" approach focuses on interpersonal harmony with an emphasis on teaching about the differences between the groups. These approaches agree that differences in the cultures of schools and students' families, among other things, may get in the way of their access to equal educational opportunity. Regarding the South Korean context, the participants also view that the cultural differences between the mainstream Korean culture of the school and the different cultures of the multicultural students is an important cause of the struggles facing the multicultural students in schools. Because the cultural difference was seen as the problem, a solution was to reduce the differences. To reduce differences, they mentioned bringing in members of the community to teach the languages and cultures of the multicultural students' families. The goal is to familiarize the mainstream students with such differences as a way to promote understanding, respect and tolerance towards diversity.

While these two approaches have their own merits, many scholars (Grant \& Sleeter, 2010; Neito, 1998; Grant \& Ladson-Billings, 1997) argue that they do little to promote social harmony. For instance, Neito (1998) argues that the multicultural approaches that promote understanding, tolerance, and even friendship are actually a low level of multicultural support that leads to "an acceptance of the status quo but with slight accommodation to difference (p. 7)." In this view, the fundamental problem facing the multicultural students is not the differences in cultures but the power relations that positions multicultural students as dominated and subjugated, quoting differences as the reason. It is the forces that narrowly define authentic or real Koreans to highlight cultural others while positioning the teachers and the students who are the members of the Danil Minjok, like the respondents, in a position of power to decide whether or not to understand, respect, or tolerate the differences of the multicultural students. Supporting the argument that there is resistance to ideological change, over $35 \%$ percent of the teachers felt uncomfortable about and over $54 \%$ of them felt undecided about the demographic changes and the increasing diversity in South Korea. This suggests that an overwhelming number of teachers in the study were less willing to critically evaluate the notion of Danil Minjok ideology in defining who real Koreans are. Without addressing the issue of Danil Minjok, it appears that multicultural education as understood by 
the respondents as limited to "feel good" activities that superficially "band-aid" over painful experiences of the marginalized and dominated students (Nieto, 1998).

Secondly, identification of cultural difference as the resistance to ideological change is coupled with the resistance to pedagogical change as shown in the contradiction in the stated problem and approach. When asked about the problems facing the multicultural students, the teachers who had experience with multicultural students identified academic achievement to be a bigger issue than their ability to function in schools. More specifically, $22 \%$ of the teachers said their multicultural students struggled academically while only $9 \%$ said socially. Put differently, they have observed that the students' inability or unwillingness to perform academically was more of a problem but sought to address social issues through multicultural education. This suggests a number of possible explanations.

One possible explanation is that they have identified social difficulties in terms of unfair treatment, both in and out of schools, as a source of their academic difficulties as discussed above. The other possible explanation is the reduction of multicultural education involving cultural and social enrichment that has little to do with academics. These two possibilities rationalize the stated goal of multicultural education to reduce differences for social harmony as a way to increase academic motivation. Still, the other possibility is the understanding of good teaching to mean the delivery of knowledge instead of advocating for the students. In this view, a good teacher, or effective teaching, fosters academic success in the core- or academic-subjects that the students learn in preparation for nationally standardized exams that includes a college entrance exam. The last possible explanation, related to the previous one, is the sense of powerlessness experienced by teachers working with a nationally determined curriculum in a very hierarchical school environment that leaves little room for creativity in teaching. Perhaps this is the reason why the teachers suggested teaching different cultures in non-core subjects like social studies, art, and music classes instead of incorporating multicultural education into classes like Korean, English, Mathematics and Science.

While the scope of the data is not clear as to which of the four possibilities is the main reason, there is evidence for the sense of powerlessness as the respondents said there was limited time and resources, including training, to do multicultural education. They felt that the current national curriculum that teaches to the national standardized exams needs to be changed to include multicultural approaches, but did not discuss how they can be an instrument for changing the curriculum. They pointed out that they need more resources, as in bringing in community members to teach about other cultures, but did not discuss how they can change their teaching to be more inclusive. They talked about more real life training and professional development to better deal with specific situations, but did not consider more systematic issues like institutional biases and prejudices that make it difficult for multicultural students to succeed academically in their schools. Moreover, they stressed the need for changes in the mindset of South Koreans, but did not articulate how their teaching can be the catalyst for a broad societal change. All these suggest that there is resistance or a sense of powerlessness in making or advocating the needed pedagogical change to foster academic success. 
With the observed resistance to both ideological and pedagogical changes, it is our argument that multicultural education in South Korea needs to undergo what Gorski (2006) calls "politicalization" as a way to reframe teachers' work towards promoting equity and justice in education. In critiquing the state of multicultural education in American schools, he argues that multicultural educators gradually drifted away from its origin as a social movement as they became more focused on improving social relations without considering institutional biases. As an example, professional development and teacher training sought to "understand" Latino students without engaging in a meaningful dialogue about racism in school policy. He also argues that there is a "whitening of the field" where the members of the dominant group dictate the aims and the meaning of multicultural education. As the world is portrayed from the dominant group's perspective that focuses on the struggles, the attention is shifted away from the effects of privilege that the educators enjoy and positions them as innocent bystanders within the power relations. We believe that these assertions are applicable in the South Korean context as well.

While South Korean multicultural education is a recent phenomenon, there is a long tradition of reforming the society through education. Such was the case when educators stood at the forefront of a political movement for democracy, along with other activists, in the 1980s against military dictators. Similarly, educators stood alongside the independence fighters against Japanese colonial powers in the early 1900s. From this tradition, the educators viewed their teaching as a means to empower themselves and their students as they prepared them to be the catalysts for social action. We argue that today's educators in South Korea must locate their multicultural education within this tradition that views teaching as a tool for societal change. To do so, they need to reevaluate their ideology towards increasing diversity and engage in an authentic conversation regarding the meanings and implications of Danil Minjok as the criteria for being authentic Koreans. They also need to locate themselves in the power relations that privileges them as legitimate Danil Minjok Koreans, while disadvantaging their multicultural students as cultural others. When these take place, the multicultural educators in South Korea can become allies to their academically and socially marginalized multicultural students. These multicultural educators are more than compassionate educators who are waiting for the societal changes to take place while overwhelmed with a sense of limitations in what they can do. Instead, they would effectively argue and demand for more professional development and resources that would benefit these students and meaningfully facilitate bringing justice and equity into Korean education. Such educators would aim beyond improving academic achievement and social adjustment of multicultural students. They would become actively involved in bringing about social changes. This would empower today's increasing number of multicultural students and their families to critique and challenge the meaning of authentic Koreans beyond the oppressive implications of Danil Minjok that marginalizes many members of Korean society. 


\section{Conclusion}

In sum, this article looked at the attitudes of South Korean educators regarding the rapid increase in diversity and multicultural education in their schools and society using a survey of 86 in-service teachers in three cities in South Korea. The results showed that there was evidence of resistance to both ideological and pedagogical changes as they felt both positive and ambivalent about the role and the possibility of multicultural education in their teaching. Using the view of multicultural education as a tool to promote social justice, we argued for what Gorski (2006) called "politicalizing multicultural education”. We argue that South Korean educators should locate themselves in the power relations as beneficiaries of the forces that marginalize their multicultural students and open the possibility of working with, instead of for, the multicultural students as allies to go a step closer towards justice and equity in South Korean schools and society.

As South Korea continues to undergo rapid and diverse demographic changes, South Korean teachers are at a crossroads regarding multicultural education. On one hand, multicultural education can become a tool to rationalize and justify current forces that marginalize the growing number of multicultural students in schools as less than authentic Koreans. Such is the case regarding the state of multicultural education according to some, as it becomes conservatized to move away from justice and equity. On the other hand, multicultural educators can locate their teaching within South Korea's tradition of viewing education as an act of leading and changing society to empower the educators who challenge and critique forces that oppress their multicultural students and others who face both academic and social marginalization.

One possible research implication of this study is the need for designing more specific and detailed instructions for multicultural education that takes this kind of approach and engaging in an ethnographic study that takes a close look at the politicalized multicultural approaches that place this type of practice in a classroom setting. Such a study could inform what more progressive and dynamic multicultural education can look like in a classroom in addition to documenting the possible transformation. Also, similar studies on current multicultural education in schools can also be useful in understanding the possibilities and limitations of multicultural education in South Korea. A close look at the Koreanization of multicultural students taking place in school can inform multicultural educators to improve their teaching with an eye towards social justice and equity in education for both teachers and students.

\section{Acknowledgment}

This research study was funded by a grant from the Benjamin V. Cohen Peace Fellowship Program. 


\section{References}

Ahn, B. H. (2009). A study on the approaches to multicultural education and the tasks of the Korean multicultural education. Korean Education Forum, 2, 155-177.

Banks, J. A. (2002). Race, knowledge construction, and education in the United States: Lessons from history. Race, Ethnicity and Education, 5(1), 228-39. http://dx.doi.org/10.1080/13613320120117171

Charmaz, K. (2005). Grounded theory in the 21stcentury. In Norman K. Denzin, \& Yvonna S. Lincoln (Eds.), (2005). The Sage handbook of qualitative research. Sage Publications.

Choi, J. (2010). Educating citizens in multicultural society: The case of South Korea. Social Studies, 101, 174-179. http://dx.doi.org/10.1080/00377990903284153

Davidman, L., \& Davidman, P. (1997). Teaching with a multicultural perspective: A practical guide. New York: Longman.

Denzin, N., \& Lincoln Y. (Eds.). (2005). The Sage handbook of qualitative research. Sage Publications.

Fass, P. (1989). Outside in: Minorities and the transformation of American education. New York: Oxford University Press.

Fink, A. (2002). How to ask survey questions (Vol. 4). Sage Publications.

Fowler, F. J. (2014). Survey research methods (Vol. 1). Sage Publications.

Freire, P. (1999). Pedagogy of the oppressed (30 th anniversary ed.). New York: Continuum.

Glaser, B. G. (2008). Conceptualization: On theory and theorizing using grounded theory. International Journal of Qualitative Methods, 1(2), 23-38.

Glaser, B. G., \& Strauss, A. L. (2009). The discovery of grounded theory: Strategies for qualitative research. Transaction Publishers.

Gorski, P. C. (2006). Complicity with conservatism: The de-politicalizing multicultural and intercultural education. Intercultural Education, 17(2), 163-177. http://dx.doi.org/10.1080/14675980600693830

Grant, C. (1994). Challenging the myths about multicultural education. Multicultural Education, 2(2), 4-9.

Grant, C. A., \& Ladson-Billings, G. (1997). Dictionary of Multicultural Education. Phoenix, AZ: Oryx Press, Inc.

Grant, C. A., \& Sleeter, C. E. (2010). Race, class, gender and disability in the classroom. In J. A. Banks \& C. A. M. Banks (Eds.), Multicultural education: Issues and perspectives (7th ed., pp. 59-82). Hoboken, NJ: John Wiley \& Sons.

Kang, S. (2010). Multicultural education and the rights to education of migrant children in 
South Korea. Educational Review, 62(3), 287-300. http://dx.doi.org/10.1080/00131911.2010.503599

Kincheloe, J. L. (2008). Knowledge and critical pedagogy: An introduction. Dordrecht, London: Springer. http://dx.doi.org/10.1007/978-1-4020-8224-5

Ladson-Billings, G. (1995). But that's just good teaching! The case for culturally relevant pedagogy. Theory Into Practice, 34(3), 159-165. http://dx.doi.org/10.1080/00405849509543675

Lee, S. J. (2005). Up against Whiteness: Race, school, and immigrant youth. New York: Teachers College Press.

Lee, Y., \& Shon, Y. (2011). Critical approaches to multicultural education and their implicationsto the South Korean multicultural education. International Journal of Early Childhood Education, 17(1), 265-282.

Lew, J. (2006). Burden of acting neither White nor Black: Asian American identities and achievement in urban schools. The Urban Review, 38(5), 335-352. http://dx.doi.org/10.1007/s11256-006-0040-8

Lim, T. (2010). Rethinking belongingness in Korea: Transnational migration, "migrant marriages" and the politics of multiculturalism. Pacific Affairs, 83(1), 51-71. http://dx.doi.org/10.5509/201083151

Ministry of Education \& Human Resources Development (MEHRD). (2006, 2007, 2008 \& 2009). Educational support for children from multicultural backgrounds. Seoul, Korea: Republic of Korea, Human Resources Policy Bureau.

Ministry of Education, Science, and Technology (MEST). (2008). Multicultural family students education plan. Seoul, Korea: Republic of Korea, MEST.

Moh, K. H. (2009). Current states and tasks for multicultural teacher education. Korean Teacher Education Research, 26(4), 245-270.

Moon, S. (2010). Multicultural and global citizenship in the transational age: The case of South Korea. International Journal of Multicultural Education, 12(1), 1-15.

Nieto, S. (1996). Affirming diversity: The sociopolitical context of multicultural education. White Plains, NY: Longman Publishers

Nieto, S. (1998). Affrimation, solidarty, and critique: Moving beyond tolerance in education, In E. Lee, D. Menkart, \& M. Okazawa-Rey (Eds.). Beyond Heroes and Holidays: A practical guide to K-12 anti-racist, multicultural education and staff development. D.C.: Network of Educations on the America

Olneck, M. (2004). Immigrants and education in the United States. In J. Banks \& C. A. M. Banks (Eds.), Handbook of research on multicultural education (2nd ed., pp. 381- 404). San Francisco: Jossey-Bass. 


\section{Macrothink}

International Journal of Education ISSN 1948-5476 2015, Vol. 7, No. 1

Olsen, L. (1997). Made in America: Immigrant students in our public schools. New York: The New Press.

Park, Gilbert C. (2011) Becoming “model minority”: Korean immigrants’ acquisition, construction, and enactment of an American identity in an inner-city school. The Urban Review, 43(5), 620-635. http://dx.doi.org/10.1007/s11256-010-0164-8

Portes, A., \& Rumbaut, G. R. (2001). Legacies: The story of the immigrant second generation. London, UK: University of California Press.

Rodriguez, A. J. (1998). Strategies for counterresistance: Towards sociotransformative constructivism and learning to teach science for diversity and for understanding. Journal of Research in Science Teaching, 36(6), 589-622. http://dx.doi.org/10.1002/(SICI)1098-2736(199808)35:6<589::AID-TEA2>3.0.CO;2-I

Roediger, D. (2005). Working toward whiteness: How America's immigrants became white. New York: Basic Books.

Sleeter, C. E. (2005). Un-standardizing cur-riculum: Multicultural teaching in the standards-based classroom. New York: Teachers College Press.

Tschong, Y. (2009). 한국사회의 다문화화에 대한 교육학적 성찰 [Educational reflection on the multiculturalization of the Korean society]. 교육철학 [Educational Philosophy], 44, 113-137.

Tuan, M. (1998). Forever foreigners or honorary whites: The Asian ethnic experience today. New Brunswick, NJ: Rutgers University Press.

Watson, S. L., Park, G., \& Lee, H. (2011). Pre-service teachers' awareness and attitudes on South Korea's increasing cultural and ethnic diversity and the role of multicultural education in K-12 schools. International Journal of Education, 3(2), 1-19.

Won, S. (2008). 다문화시대 소수자 정책의 차별적 포섭과 배제: 외국인 대상 정책을 중심으로 한 탐색적 접근 [Differentiated inclusion and exclusion of policy for marginalized groups in multicultural age]. 한국행정학보 [Korean Journal of Administration], 42(3), 29-49.

\section{Copyright Disclaimer}

Copyright for this article is retained by the author(s), with first publication rights granted to the journal.

This is an open-access article distributed under the terms and conditions of the Creative Commons Attribution license (http://creativecommons.org/licenses/by/3.0/). 